\title{
Transient model of heat pump cycle
}

\section{Robert MATYSKO}

DOI: 10.30464/jmee.2018.2.2.139

Cite this article as:

Matysko R. Transient model of heat pump cycle. Journal of Mechanical and Energy Engineering, Vol. 2(42), No. 2, 2018, pp. 139-146.

\section{VOLUME 2(42) | No. 2 | JUNE 2018}

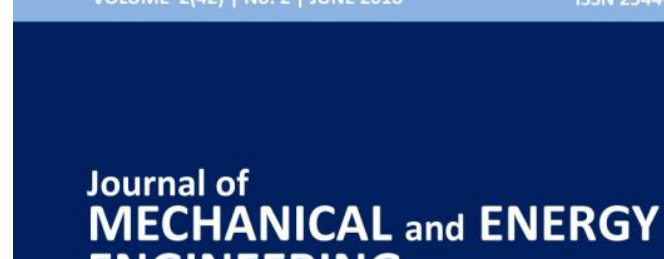

\section{ENGINEERING}

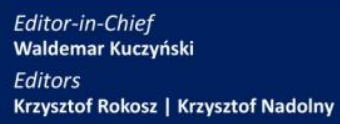

\section{Journal of Mechanical and Energy Engineering}

Website: jmee.tu.koszalin.pl

ISSN (Print): 2544-0780

ISSN (Online): 2544-1671

Volume: 2(42)

Number: 2

Year: 2018

Pages: $139-146$

\section{Article Info:}

Received 6 March 2018

Accepted 26 April 2018

\section{Open Access}

This article is distributed under the terms of the Creative Commons Attribution 4.0 (CC BY 4.0) International License (http://creativecommons.org/licenses/by/4.0/), which permits unrestricted use, distribution, and reproduction in any medium, provided you give appropriate credit to the original author(s) and the source, provide a link to the Creative Commons license, and indicate if changes were made. 


\title{
TRANSIENT MODEL OF HEAT PUMP CYCLE
}

\author{
Robert MATYSKO ${ }^{1 *}$ \\ ${ }^{1 *}$ The Szewalski Institute of Fluid Flow Machinery, Polish Academy of Science, Turbine Department, Centre \\ of Heat and Power Engineering, matyskor@imp.gda.pl
}

(Received 6 March 2018, Accepted 26 April 2018)

\begin{abstract}
This paper introduce a transient model of the propane heat pump cycle. The heat pump cycle model includes: a compressor model, a condenser model in lumped parameters, an evaporator model in lumped parameters, an expansion valve model, a heat source model (cooling chamber), a PID control system for heat recovery from superheated refrigerant vapour. The model allows estimate inertia of the heat pump cycle with the system of the heat recovery from superheated propane vapor. The presented theoretical model can determine unsteady and steady state conditions of the different subsystems in the heat pump cycle (condenser, evaporator, compressor). The article presents the results of calculations and determines the time of reaching steady states of the key systems of the heat pump system. The article also presents (in a graphical form) the behavior of the system where the setting was changed after reaching the steady state after $2000 \mathrm{~s}$ from $50 \mathrm{~kW}$ to $40 \mathrm{~kW}$ at the thermal load of the additional heat recovery exchanger.
\end{abstract}

Keywords: heat pump; transient model; refrigeration cycle; MIMO controller

\section{INTRODUCTION}

Some theoretical transient models are used in refrigeration and heat pump technology. Heat pumps (refrigeration cycles) except receiving low temperatures in cooling chambers, or air conditionings systems enable to receive high temperatures in a condensers (fig. 1). A dynamic thermal model for water-water refrigeration plant is described for the purpose of investigating control system tuning and performance in [1]. A dynamic model of air-to-water dual-mode heat pump with a screw compressor is presented in [2]. The steady-state models are applied for compression, throttling, and leakage processes in [2]. The paper [3] presents two numerical models to simulate the transient and steady state behavior of a vapor compression refrigeration system. In the paper [3], the condenser and the evaporator were divided into a few number of control volumes. The motor and compression characteristics of water source heat pumps were modeled in [4] to include the coupling between the motor speed and the torque characteristics and compression characteristics. Paper [5] presents an auto regressive moving-average model with exogenous inputs and a digital controller for a household refrigeration system that uses a variable speed compressor. The results of the experimental tests showed in [5] that the model reproduces with a high accuracy the dynamic behavior of the refrigeration system with less than $7 \%$ error. In the paper [6], the three forms of momentum equation are numerically studied. The transient results without any pressure drop give a very close estimation of control parameters in comparison with the results taking into account the transient or a steady-state pressure drop. The [7] work presents a semi-empirical mathematical model to simulate the unsteady behavior of mass flow rate and the power of reciprocating compressors. It was found that the semi empirical model proposed in [7] can be satisfactorily applied to the dynamic simulations of the whole refrigeration system. A transient response model for the refrigeration cycle has been developed in the paper [8]. The model contains four sub-models representing the condenser, evaporator, compressor and the electronic expansion valve The condenser and the evaporator are developed based on the moving-boundary formulation. Paper [9] presents a dynamic model of a transcritical $\mathrm{CO}_{2}$ ejector expansion refrigeration cycle. The mathematical models for gas cooler, evaporator and separator are formulated by using the mass and energy conservation equations. The compressor and expansive valve are modelled in a set of algebraic equations. 


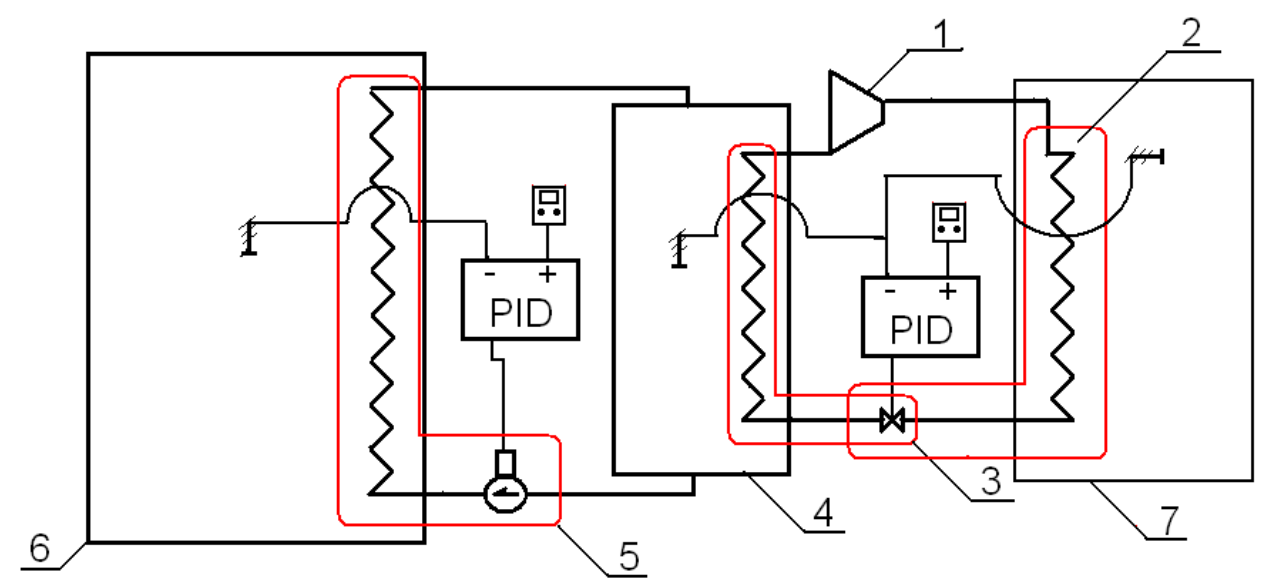

Fig. 1. Heat pump cycle as cooling and heating devices; 1 - compressor, 2 - condenser, 3 - expansion valve; 4 - chill container, 5 - cold medium pump, 6 - cooling chamber, 7 - heated room

The bases of the theoretical model for the reciprocating compressor dead volume ratio and the friction factor influence in the compression cycle is discussed in [10]. The study [11] is related to modelling and experimental characterizations of an open display cabinet in a transient state. The model can be used to predict the dynamic behavior during the on-off process, defrost operations and power failure. The whole refrigeration system is modelled in a paper [12], taking into account the hourly weather data and calculating the hourly cooling load demand from display cabinets and cold rooms equipment. Simulations in [12] consider a simple double compression cycle with a liquid receiver, and other options including an auxiliary compressor. The paper [13] presents the modelling of a refrigeration container for use as a reference for energy-optimizing controller design. The paper [14] presents a simulation methodology, developed to analyze the compressor in transients effects that occur during the start-up and shutdown. The dynamic refrigeration cycle is developed as a high fidelity simulator in the [15], and its performance is verified against the vehicle refrigeration unit. The study [16] investigates the transient impact of the ambient temperature and precooling processes in $\mathrm{CO}_{2}$ refrigeration system. The [17] paper described a hybrid dynamic model for transient simulation of refrigeration systems as well as dynamic experiments that have been performed on an air/water heap pump. The machine under consideration is made of an evaporator, a condenser, an expansion valve, a variable speed scroll compressor and a receiver.
The heat pump cycle $[17,18]$ allows obtaining a high temperature in the room from the heat transfer process in the condenser. The condensation process occurs near the steady temperature (in the range from 20 to $40^{\circ} \mathrm{C}$ ).

In technical applications, high-temperature obtained from superheating vapor from condenser is sometimes used for heating, but heat recovery from these way make sense only in large objects. For example, the process of the heat recovery from superheated vapor can be realized through an additional controlled heat exchanger.

The example control set for the condensation process and heat recovery from the superheated refrigerant vapor is introduced in Fig 2. In this configuration, the temperature of superheated vapor depends from air mass flow through condenser.

An installation like this makes it possible to obtain water with a higher temperature than refrigerant condensation temperature.

This article presents a heat pump model where equations were written in a form that can be used in the Matlab Simulink software. The model can be used to simulate starting and stopping conditions of the heat pump system. The leading contribution of the author to the development of the field of refrigeration is a mathematical model allowing to determine the time of inertia during the exploitation of the refrigeration cycle.

In the paper, the dynamic response of the heat pump system for a step change in heat load was calculated. Changing the heat load was taking place in an additional heat exchanger that was installed as a heat recovery system from superheated steam. 


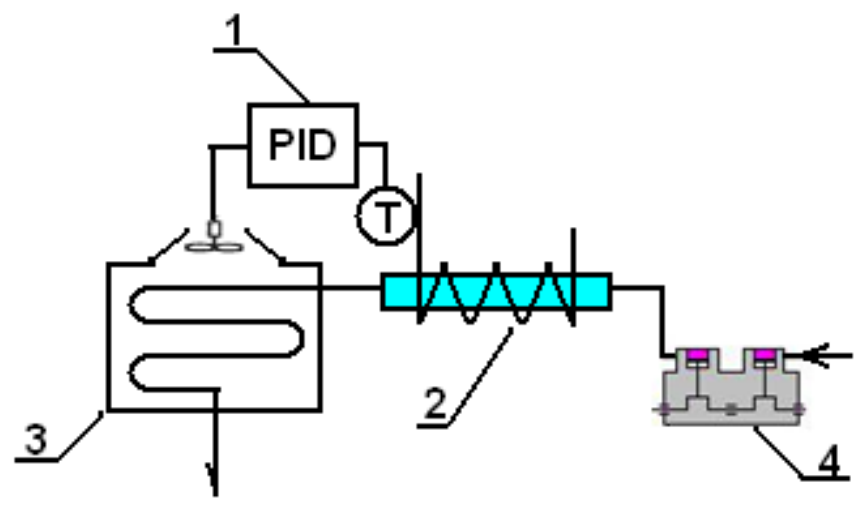

Fig. 2. Example control set for heat recovery from superheated vapour [6]: 1 - temperature control set, 2 - vapour cooler, 3 - main condenser, 4 - compressor

\section{MODEL OF THE HEAT PUMP}

Stabilization of the heat transfer process in the highest superheated vapor temperature range is depend from variable demand for the heating process and the controller type. In introduced model of heat pump installation MIMO-PID controller [19, 20] was apply (Fig 3).

This controller allows one to receive a set for:

- heat flux obtained from superheated vapor,

- temperature in cooling chamber,

- condensation temperature.

In the presented model, the following assumptions were accepted:

- an ideal refrigeration cycle (without vapor superheating in evaporator and liquid subcooling in condenser),

- condenser and evaporator model was described by lumped parameters,
- compressor work and expansion valve performance depends from parameters in heat exchanger,

- heat transfer parameters in evaporator and condenser taken as constant mean value.

The refrigeration cycle was described by the following equation.

Condenser:

- mass balance in condenser:

$\frac{d M_{s k}}{d t}=\left(\dot{m}_{s k, \text { in }}-\frac{d M_{s k}}{d t}\right)+\left(\frac{d M_{s k}}{d t}-\dot{m}_{s k, \text { out }}\right) ;$

- condensation process:

$\frac{d T_{s k}}{d t}=\frac{1}{\left(\frac{{ }^{c}, v+c_{p, l}}{2}\right) M_{s k}}\left[A_{\text {wall }} k_{s k-w a l l}\left(T_{w a l l}-T_{s k}\right)+\right.$

mskhv-hl;

- heat transfer in condenser wall:

$\frac{d T_{\text {wall }}}{d t}=\frac{1}{M_{\text {wall }} c_{p, \text { wall }}}\left[A_{\text {wall }} k_{\text {sk-wall }}\left(T_{s k}-T_{\text {wall }}\right)+\right.$

$\left.A_{\text {wall }} k_{\text {wall-water }}\left(T_{\text {water }}-T_{\text {wall }}\right)\right]$;
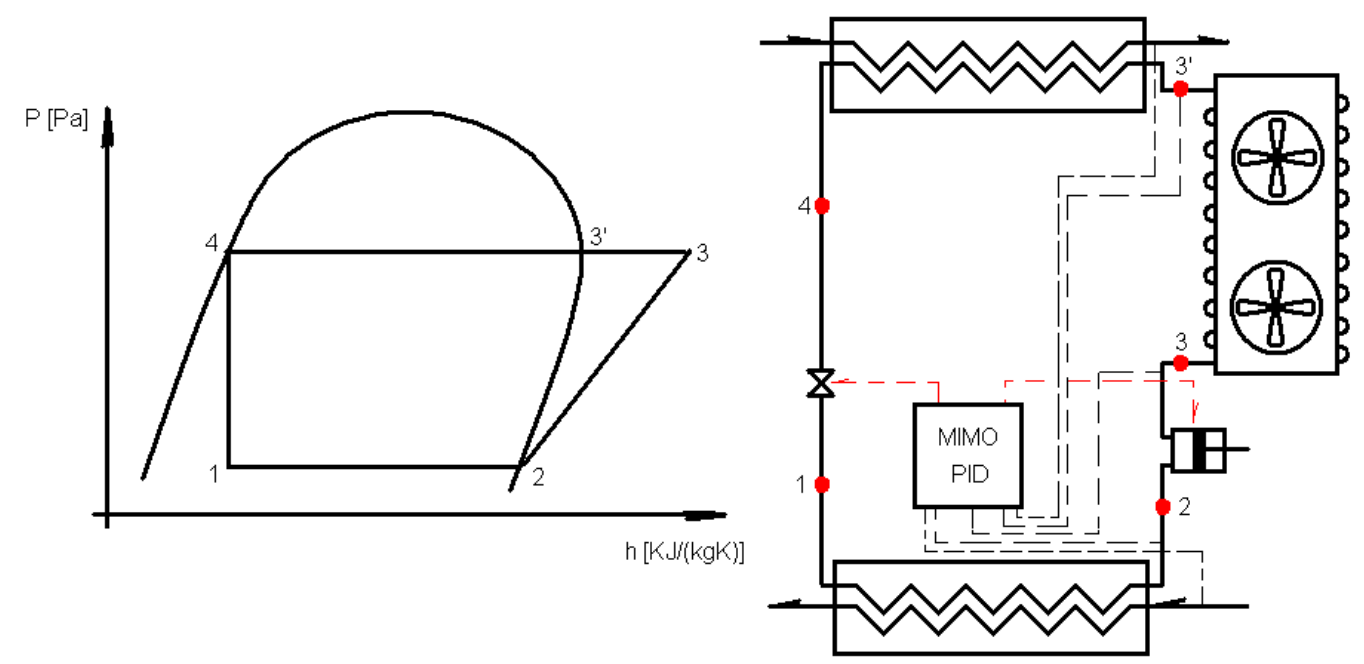

Fig. 3. Configuration for MIMO-PID control of refrigeration cycle 
- water cooling:

$\frac{d T_{\text {water }}}{d t}=\frac{1}{M_{\text {water }} c_{p, \text { water }}}\left[c_{p, \text { water }} \dot{m}_{\text {water }}\left(T_{\text {water }, \text { in }}-\right.\right.$

Twater+kAizolTizol-Twater+kwall-waterAwal

ITwall-Twater;

- heat transfer in condenser insulation:

$\frac{d T_{i z o l}}{d t}=\frac{1}{M_{\text {izol }} c_{p, i z o l}}\left[A_{\text {izol }} k_{\text {water-izol }}\left(T_{\text {water }}-T_{\text {izol }}\right)+\right.$

Aizolkizol-powTpow-Tizol;

Evaporator: - mass balance in evaporator:

$\frac{d M_{b}}{d t}=\left(\dot{m}_{b, \text { in }}-\frac{d M_{b}}{d t}\right)+\left(\frac{d M_{b}}{d t}-\dot{m}_{b, o u t}\right) ;$

- evaporation process:

$\frac{d T_{b}}{d t}=\frac{1}{\left(\frac{{ }^{c} p, v+c p, l}{2}\right) M_{b}}\left[A_{w a l l} k_{b-w a l l}\left(T_{w a l l}-T_{b}\right)+\right.$ $m b h v-h l$;

- heat transfer in evaporator wall:

$\frac{d T_{\text {wall }}}{d t}=\frac{1}{M_{\text {wall }} c_{p, \text { wall }}}\left[A_{\text {wall }} k_{b-\text { wall }}\left(T_{b}-T_{\text {wall }}\right)+\right.$

Awallkwall-olTol-Twall;

- heating process from thermal loading in evaporator:

$\frac{d T_{o l}}{d t}=\frac{1}{M_{o l} c_{p, o l}}\left[c_{p, o l} \dot{m}_{o l}\left(T_{o l, i n}-T_{o l}\right)+k A_{p o w}\left(T_{i z o l}-\right.\right.$

Tol+kAwall-olTwall-Tol;

- heat transfer in condenser insulation:

$\frac{d T_{i z o l}}{d t}=\frac{1}{M_{\text {izol }} c_{p, i z o l}}\left[A_{i z o l} k_{o l-i z o l}\left(T_{o l}-T_{i z o l}\right)+\right.$

Aizolkizol-powTpow-Tizol.

Compressor mass flow rate:

$$
\dot{m}_{c o m}=V_{v} \varrho_{v}\left(1-\frac{V_{v}}{V_{s}}\right)\left[\left(\frac{P_{s k}}{P_{b}}\right)^{\frac{1}{n}}-1\right] .
$$

Mass flow rate through the expansion valve:

$$
\dot{m}=K A \sqrt{2 \varrho_{l} \Delta P}
$$

PID regulator:

$$
G_{P I D}(s)=K_{p}+\frac{K_{i}}{s}+K_{d} s
$$

Thermal loading in cooling chamber $[19,20]$ :

$$
\begin{gathered}
M_{t l} c_{p, t l} \frac{d T_{t l, i}}{d t}= \\
A \frac{\lambda}{\Delta x}\left(T_{t l, i+1}-T_{t l, i}\right)+A \frac{\lambda}{\Delta x}\left(T_{t l, i-1}-T_{t l, i}\right) .
\end{gathered}
$$

Cooling chamber and heating room:

$$
M_{i, c c} c_{p, i, c c} \frac{d T_{c c}}{d t}=\sum k A\left(T_{i j}-T_{c c}\right) .
$$

Intermediary medium between cooling chamber and evaporator, (condenser and heating room) [19, 20]:

$A \varrho c_{p} \frac{d T_{o l}}{d t}=2 w S \varrho c_{p} \frac{T_{o l+1}-T_{o l}}{d x}-2 w S \varrho c_{p} \frac{T_{o l}-T_{o l-1}}{d x}+$
$k A\left(T_{\text {wall }}-T_{o l}\right)$.

\section{CALCULATION RESULTS}

Figures 4, 5, 6 show a change of temperature and heat flux distribution in time for two tune heat flux received from superheated refrigeration vapor $(50 \mathrm{~kW}$ in start; and $40 \mathrm{~kW}$ after 2000 sek). This results present direct dependence in controlled parameters. Heat flux obtained from additional heat exchanger (superheated vapor zone) depends from compression temperature, and this has influence on entire refrigeration cycle.

The most significant effects which were received during the calculation is the slight increase in thermal load temperature, and also significant changes in evaporators and condensers temperature. Change of the heat flux in additional exchanger (superheated vapor) has impact on quality in cooling chamber room.

The steady state temperature $\left(5^{\circ} \mathrm{C}\right)$ in the evaporator was reached after $1,500 \mathrm{sec}$ and steady state temperature in the condenser $\left(35^{\circ} \mathrm{C}\right)$ was reached after $1,700 \mathrm{~s}$ from the start-up of the system. Steady state at compressor outlet $\left(50^{\circ} \mathrm{C}\right)$ was reached after $1000 \mathrm{~s}$.

The steady state temperature in the refrigeration chamber $\left(10^{\circ} \mathrm{C}\right)$ was reached after $2000 \mathrm{sec}$ from the start-up of the refrigeration system.

\section{CONCLUSIONS}

The presented work demonstrates the impact of heat recovery control for evaporation and condensation temperature in the heat pump cycle and thermal loading in the cooling chamber. Interconnection between the controlled parameters may lead to stability failing in heat pump cycle. For MIMO-PID regulation in heat recovery was observed:

- temperature of superheated vapor deviation is decreasing when rising proportional component in MIMO-PID regulator occur;

- smaller proportional component in MIMO-PID regulator restores stability in heat pump cycle;

- integration component in MIMO-PID regulator allows more accurate static adjustment in controlled parameter (smaller displacement in control process)

- differentiating component in MIMO-PID regulator extends bandwidth of preserving stability when change of setting for heat recovery occur. 

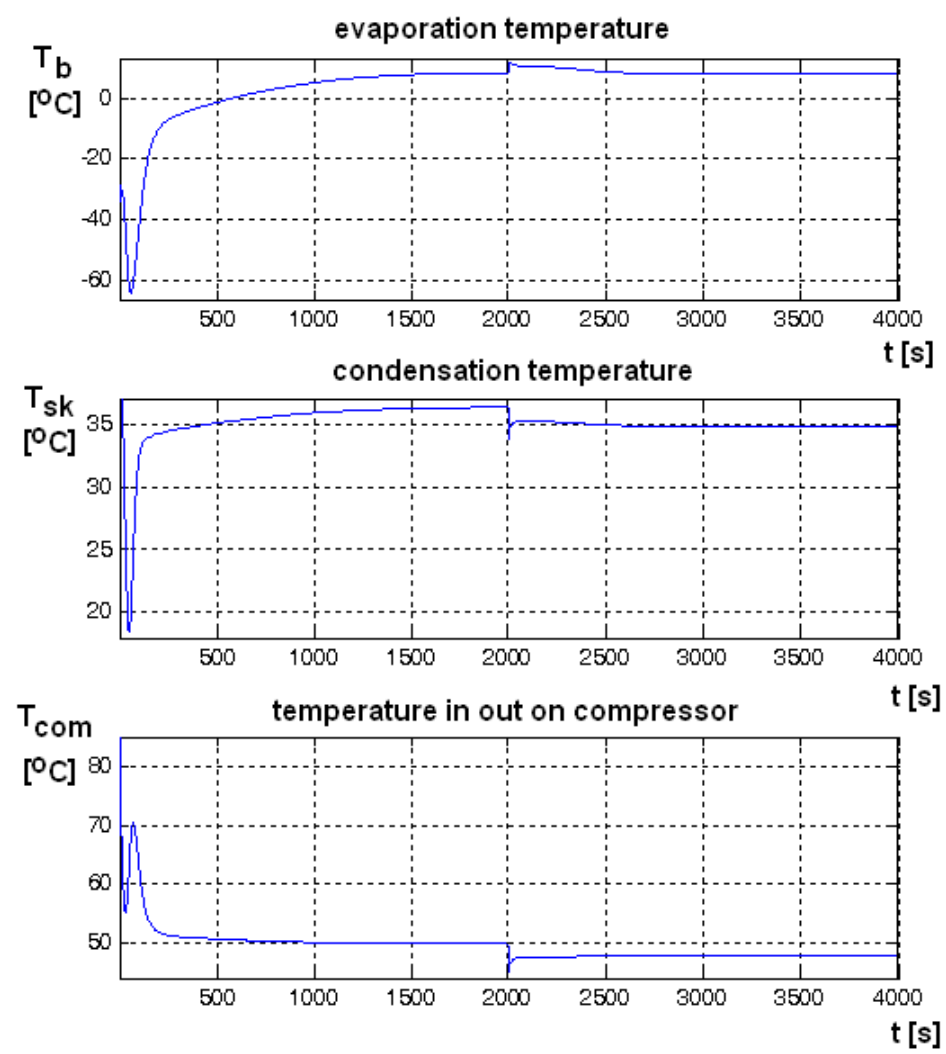

Fig. 4. Refrigerant temperature change in time for refrigeration cycle
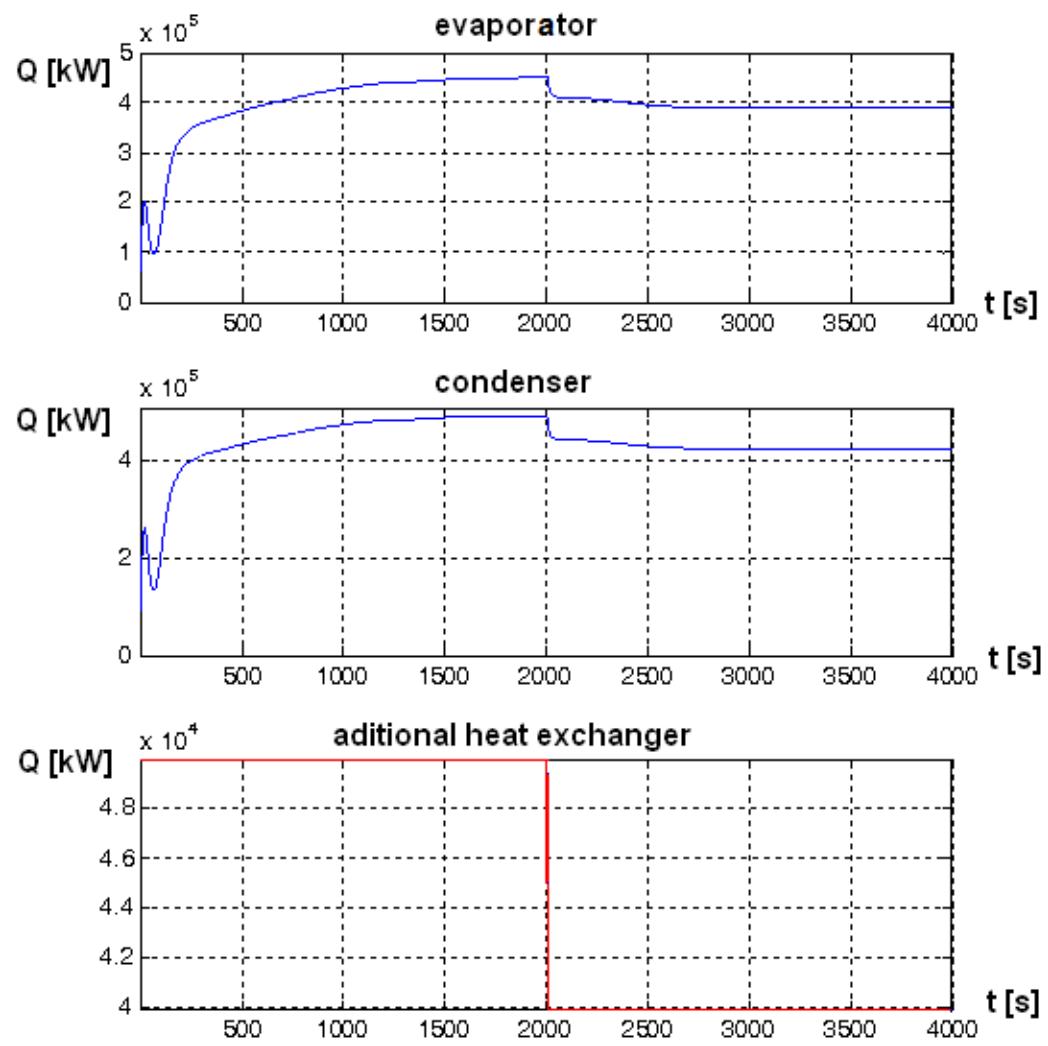

Fig. 5. Heat flux distribution in time for refrigeration cycle and heat recovery 


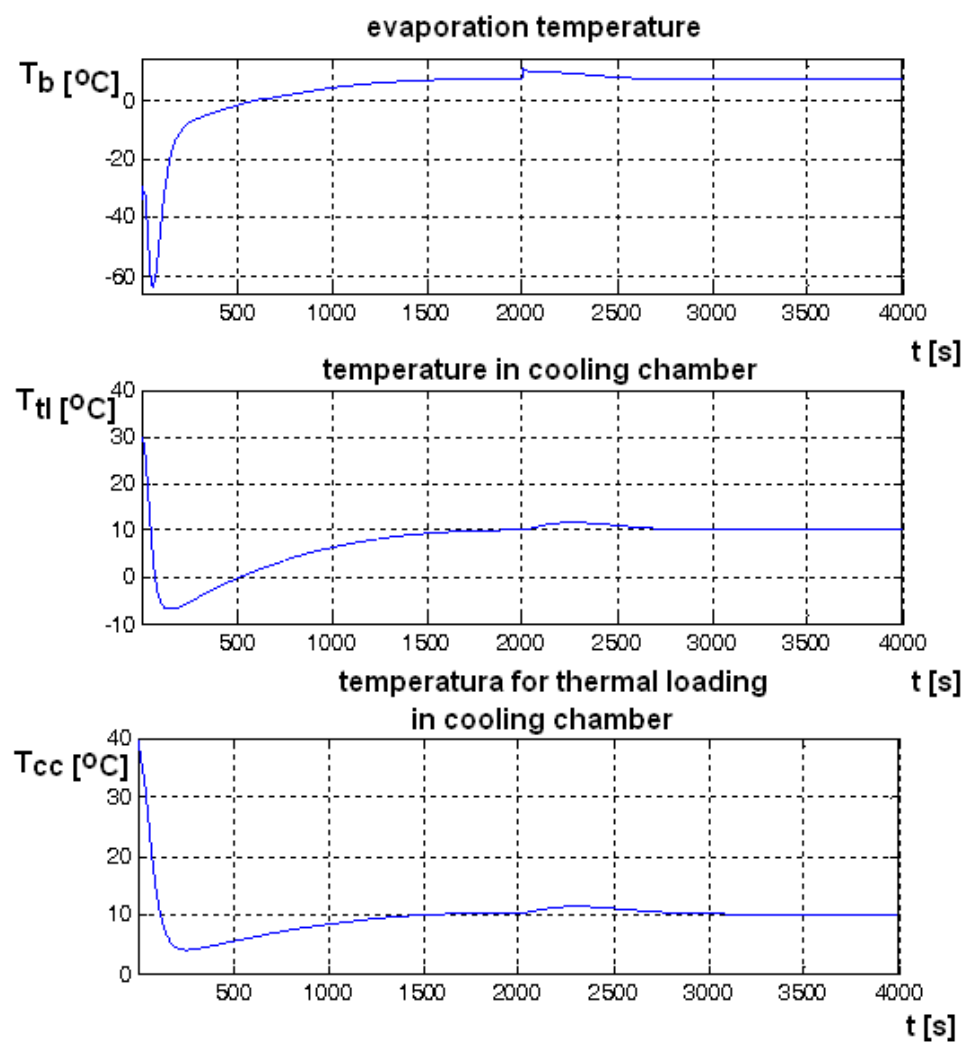

Fig. 6. Temperature change in time for thermal loading

\section{Nomenclature}

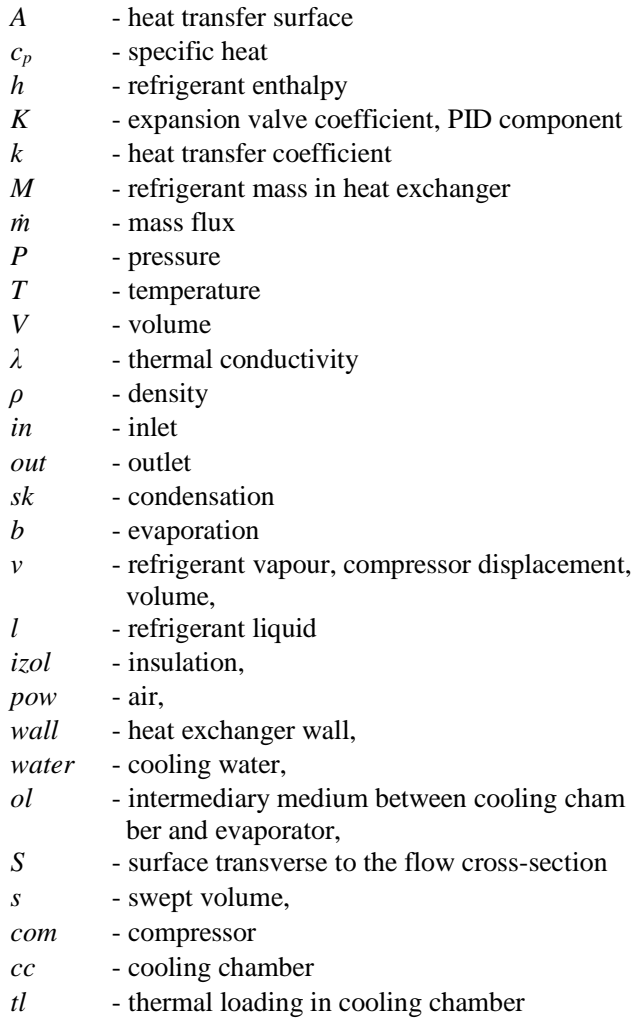

\section{References}

1. Underwood C.P., 2001, "Analysis multivariable control of refrigeration plant using MATLAB/SIMULINK", Seventh international IBPSA Conference Rio de Janeiro, Brazil.

2. Fu L., Ding G., Zhang C. 2003, "Dynamic simulation of air-to-water dual-mode heat pump with screw compressor", Applied Thermal Engineering 23 pp.16291645

3. Koury R.N.N., Machado L., Ismail K.A.R., 2001, "Numerical simulation of a variable speed refrigeration system"; International Journal of Refrigeration 24.

4. Xue, Zhifang; Shi, Lin, 2010 "Modeling and Experimental Investigation of a Variable Speed Drive Water Source Heat Pump" Tsinghua Science \& Technology pp. 434-440.

5. Carlos A. Piedrahita-Velasquez, Hector J. CiroVelasquez, Mario A. Gomez-Botero Identification and digital control of a household refrigeration system with a variable speed compressor, International Journal of Refrigeration 48 (2014).

6. Wei-Jiang Zhang, Chun-Lu Zhang, Guo-Liang Ding, On three forms of momentum equation in transient modeling of residential refrigeration systems International Journal of Refrigeration 32 (2009) 938 - 944.

7. Cezar O.R. Negrão, Raul H. Erthal, Diogo E.V. Andrade, Luciana Wasnievski da Silva, A semi-empirical model for the unsteady-state simulation of reciprocating compressors for household refrigeration applications Applied Thermal Engineering 31 (2011) 1114-1124.

8. Ye Yao, Weiwei Wang, Mengwei Huang, A state-space dynamic model for vapor compression refrigeration system based on moving-boundary formulation, 
International Journal of Refrigeration 60 (2015) 174189.

9. Lixing Zheng, Jianqiang Deng, Yang He, Peixue Jiang, Dynamic model of a transcritical $\mathrm{CO} 2$ ejector expansion refrigeration system, International Journal of Refrigeration 60 (2015) 247-260.

10. Jean Castaing-Lasvignottes, Stephane Gibout, Dynamic simulation of reciprocating refrigeration compressors and experimental validation International Journal of Refrigeration 33 (2010) $381-389$.

11. R. Ben-Abdallah, D. Leducq, H.M. Hoang, O. Pateau, B. Ballot-Miguet, A. Delahaye, L. Fournaison, Modelling and experimental investigation for load temperature prediction at transient conditions of open refrigerated display cabinet using Modelica environment, International Journal of Refrigeration (2018), doi: 10.1016/j.ijrefrig.2018.02.017.

12. Alessio Polzot, Paola D'Agaro, Paride Gullo, Giovanni Cortella, Modelling commercial refrigeration systems coupled with water storage to improve energy efficiency and perform heat recovery International Journal of Refrigeration 69 (2016) 313-323.

13. Kresten K. Sørensen, Morten Juel Skovrup, Lars M. Jessen, Jakob Stoustrup Modular modeling of a refrigeration container International Journal of Refrigeration 55 (2015) 17-29.

14. Rodrigo Link a, Cesar J. Deschamps, Numerical modeling of startup and shutdown transients in reciprocating compressors International Journal of Refrigeration 34 (2011) 1398-1414.

15. Tae Hoon Lim, Younggy Shin, Sanghun Kim, Chunkyu Kwon, Predictive control of car refrigeration cycle with an electric compressor, Applied Thermal Engineering 127 (2017) 1223-1232.

16. Eivind Brodal, Steve Jackson, Oddmar Eiksund Transient model of an RSW system with $\mathrm{CO} 2$ refrigeration $-\mathrm{A}$ study of overall performance International Journal of Refrigeration 86 (2018) 344355 .

17. Jing Wua, Emilie Gagniere, Francoise Couenne, Boussad Hamroun, Thierry Latour, Christian Jallut A hybrid transient model for simulation of air-cooled refrigeration systems: Description and experimental validation. International Journal of Refrigeration 53 (2015) 142-154.

18. Matysko. R. Ammonia compressor stations, Refrigeration and Air conditioning, Gdansk 2015 - in Polish.

19. Matysko R. Theoretical model of the operation parameters regulated by the MIMO and SISO system in a cooling chamber, International Journal of Refrigeration Volume 58, October 2015, Pages 53-57.

20. Matysko R. Selected issues of modeling, control and optimization of thermal cycles operating based on ORC systems, Scientific Papers of the Institute of Fluid-Flow Machinery of the Polish Academy of Sciences in Gdańsk, 2013 - in Polish.

\section{Biographical note}

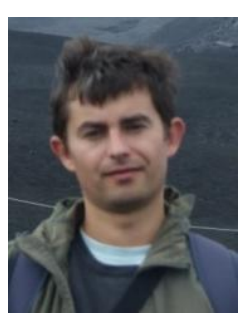

Robert Matysko is a graduate of the $\mathrm{PhD}$ study at the Faculty of Mechanical Engineering at the Koszalin University of Technology. He obtained the doctoral title in the field of Construction and Exploitation of Machines at the Koszalin University of Technology and then took a job at the Institute of Fluid-Flow Machinery of the Polish Academy of Sciences in Gdańsk. At the Institute of Fluid-Flow Machinery he obtained the title of the dr hab. Eng. in the field of Construction and Exploitation of Machines. He was the coordinator in the investment of the Research Center of the Polish Academy of Sciences in Jabłonna. He also managed the Department of Thermodynamics at IFFM-PAS. Scientific interests are related to the control and modeling of thermodynamic processes. Currently, he develops algorithms for controlling various autonomous systems. 
